\title{
Perspective - the need and prospects for negative emission technologies - direct air capture through the lens of current sorption process development
}

\author{
Matthew J. Realff', Youn Ji Min, Christopher W. Jones, and Ryan P. Lively \\ School of Chemical \& Biomolecular Engineering, Georgia Institute of Technology, Atlanta, GS 303332-0100 \\ (Received 21 August 2021 • Revised 9 September 2021 • Accepted 14 September 2021)
}

\begin{abstract}
We provide a perspective on the development of direct air capture (DAC) as a leading candidate for implementing negative emissions technology (NET). We introduce DAC based on sorption, both liquid and solid, and draw attention to challenges that these technologies will face. We provide an analysis of the limiting mass transfer in the liquid and solid systems and highlight the differences.
\end{abstract}

Keywords: Climate Change, Carbon Capture, Direct Air Capture, Modeling and Simulation

\section{INTRODUCTION}

The COVID-19 pandemic has taught us at least two important lessons about climate change. First, despite world-wide lockdowns extending for several months, global emissions of $\mathrm{CO}_{2}$ fell by only roughly $9 \%$ at the height of the pandemic in the first half of 2020 [1]. The need to reduce emissions by significantly greater than this amount to keep atmospheric warming below $+2^{\circ} \mathrm{C}$ by the end of the century should make us recognize the truly profound changes that are required in our global energy production and consumption. Second, the development of mRNA vaccines for the virus in less than a year was a remarkable engineering achievement. It was founded on several decades of research and development from the 1990's to the initial breakthrough in 2005, and based on fundamental discoveries made over decades stretching back to the discovery of mRNA at the beginning of the 1960's [2]. The mRNA vaccine technology was ready to be scaled up by massive government investment. Climate science has a similar history of discovery stretching back to the original hypothesis of the greenhouse effect of $\mathrm{CO}_{2}$ by Arrhenius published in 1896, and the measurements of $\mathrm{CO}_{2}$ concentration on Mauna Loa, which began in the 1950's. However, despite the rapid advance of renewable energy based on wind and solar power, we do not have a sufficiently diverse portfolio of technologies ready to be scaled up to the levels necessary to meet the challenges of stabilizing our $\mathrm{CO}_{2}$ concentrations in the atmosphere while simultaneously providing the ever increasing level of energy that society demands.

A missing critical component of any strategy to manage $\mathrm{CO}_{2}$ concentrations, is a scalable negative emissions technology or NET $[3,4]$. A key problem is that even though we may be able to reduce the rate of increase in $\mathrm{CO}_{2}$ by reducing emissions, this cannot reduce the concentration of existing $\mathrm{CO}_{2}$ in the atmosphere. We have a one-sided control action, and we need its complement in case we

\footnotetext{
${ }^{\dagger}$ To whom correspondence should be addressed.

E-mail: matthew.realff@chbe.gatech.edu

Copyright by The Korean Institute of Chemical Engineers.
}

overshoot levels of $\mathrm{CO}_{2}$ in the atmosphere to the point where our societal systems become over-stressed due to sea-level rise, desertification, disease range increases, storm frequency, or other changes wrought by higher radiative forcing. The need for NET's has been recognized in a recent United States National Academies report [5], and by an increasing number of papers that use integrated assessment modeling based on social sustainable pathways (SSPs) to demonstrate that reaching our climate targets is unachievable without them $[6,7]$.

There are several NET's that are under active development. Those based on bioenergy with carbon capture and storage or BECCS $[8,9]$ have been an early frontrunner, but this approach may have significant land use requirements [10]. More recent NET developments have focused on direct air capture (DAC) $[11,12]$ and mineralization [13]. There remain many challenges with these technologies, and this provides significant opportunities for chemical engineering research and development over the next decade. Furthermore, there is room for further innovative research on entirely new approaches that could see deployment multiple decades from today.

We focus this perspective on understanding the tradeoffs involved in DAC through the lens of two contrasting sorption processes, liquid absorption and solid adsorption, recognizing that this is a small slice of the potential sorption technologies, which include emerging electrochemical approaches [14]. However, several of the issues raised for sorbent-based technologies must be faced by any DAC system i.e., any system that contacts air to remove $\mathrm{CO}_{2}$ including mineralization, such as the energy and carbon footprint of the design and how the air will be efficiently contacted with the active device components.

\section{OVERALL PROCESS CONFIGURATION}

Any sorption-based process will involve at least two coupled steps. The first will be the sorption of the $\mathrm{CO}_{2}$ from the air, into the sorbent and the second desorbing it. However, it is possible that to increase process efficiency, there may be an intermediate step 


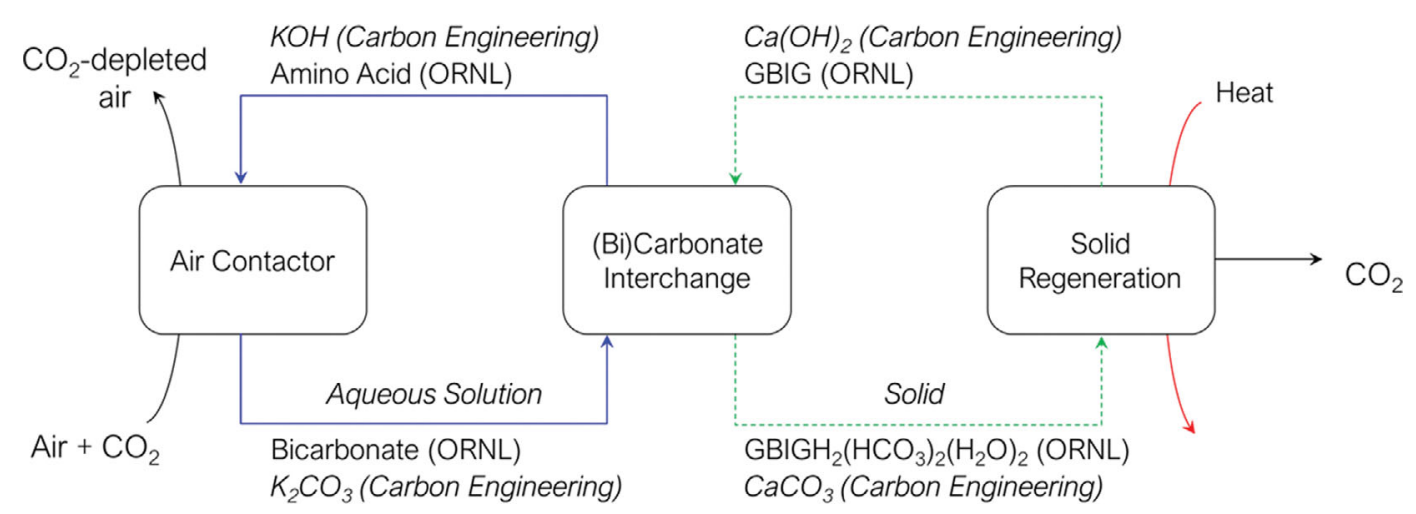

Fig. 1. Block flow diagram of liquid absorption for DAC with an intermediate exchange of the (bi)carbonate ion.

where the sorbed $\mathrm{CO}_{2}$ is transferred from the initial sorbent to an intermediate for which a regeneration process is easier to implement. This is the approach taken in the liquid absorbent process pioneered by Carbon Engineering, where the soluble $\mathrm{KOH}$ reacts to $\mathrm{K}_{2} \mathrm{CO}_{3}$ and then the carbonate ion is exchanged with $\mathrm{Ca}(\mathrm{OH})_{2}$ to produce an insoluble $\mathrm{CaCO}_{3}$ that is then heated to remove the $\mathrm{CO}_{2}$ (see Fig. 1). This exchange means that a relatively dilute solution containing the $\mathrm{K}_{2} \mathrm{CO}_{3}$ does not have to be heated, but instead a much smaller quantity of solid is heated. The use of $\mathrm{KOH}$ rather than directly using $\mathrm{Ca}(\mathrm{OH})_{2}$ is motivated by the mass transfer coefficient, for the latter being an order of magnitude lower [15]. Similarly, another liquid absorption process developed at the Oak Ridge National Laboratory (ORNL) uses a two-step absorption. Sarcosine or glycine amino acids were used as the initial absorbent with absorption capacities of $1 \mathrm{~mol} \mathrm{CO}_{2}$ per mol of amino acid and concentrations in the 1 to 2 molar range. The amino acids were then regenerated with a guanidine compound, 2,6-pyridinebis(iminoguanidine) (PyBIG) [16]. In later studies, performed at pilot scale using flue gas concentrations of $\mathrm{CO}_{2}$, solid glyoxal-bis(iminoguanidine) GBIG replaced the pyBIG [17]. The GBIG dissolves and reprecipitates producing a solid a bicarbonate salt with two bicarbonate moieties per GBIG and two water molecules. The bicarbonate salt can then be heated to $80-120^{\circ} \mathrm{C}$ to regenerate the GBIG and produce a 1:1 mixture of water and $\mathrm{CO}_{2}$; this is also depicted in Fig. 1 .

These liquid chemical looping schemes allow for a continuous process to be developed because of the movement of the sorbent from one environment to another. Similarly, one could imagine the same approach with solid adsorbents in circulating fluidized bed configurations, but the pressure drops induced in these systems are prohibitively large. Instead, solid adsorbents have been used in fixed bed arrangements with ultra-high porosity that provide low pressure drops. A cyclic batch approach is taken where a series of beds are contacted with air and then later regenerated through heating. A temperature swing adsorption process is preferred in this context. Pressure swing alone would require prohibitively deep vacuums because the near pure $\mathrm{CO}_{2}$ must exert a partial pressure below that of 400 ppm atmospheric $\mathrm{CO}_{2}$ to permit any swing from the adsorbent [18]. Hence the goal has been to identify solid adsorbents that allow for modest temperature changes associated with large changes in adsorption capacity and reasonable $\mathrm{CO}_{2}$ loadings per unit mass of adsorbent.

\section{DAC SORPTION PROCESS ENERGY EFFICIENCY}

To be efficient, sorption-based DAC systems must balance the cost of energy associated with high heats of sorption with the capital cost of materials with low capacities and rates. For liquid absorbents, in the case of the carbon engineering process, the regeneration of $\mathrm{CaO}$ from $\mathrm{CaCO}_{3}$ takes place at high temperature, $800-900{ }^{\circ} \mathrm{C}$, and in the current implementation consumes natural gas combusted in nitrogen free gas to provide the heat to generate a pure $\mathrm{CO}_{2}$ stream. This has the sensible parasitic load of heating the sorbent material to high temperature as well as the relatively high heat of reaction of $178.3 \mathrm{~kJ} / \mathrm{mol}$ to produce the $\mathrm{CaO}$, although through heat integration, some of this energy is recovered in the lime slaker where the $\mathrm{CaO}$ reacts to $\mathrm{Ca}(\mathrm{OH})_{2}$ with $63.9 \mathrm{~kJ} / \mathrm{mol}$ of energy released [19]. Moreover, there is the additional cost of an air separation unit to generate the nitrogen-free gas. The ORNL process uses a lower temperature of regeneration but has to provide energy to vaporize both the $\mathrm{CO}_{2}$ and water of crystallization. The advantage of the GBIG over the pyBIG is that the water ratio is $1: 1 \mathrm{com}$ pared to $4: 1$, which significantly improves the energy efficiency of the process. The cycle capacity, mol $\mathrm{CO}_{2}$ per mole of amino acid is unaffected at $0.2-0.3 \mathrm{~mol} \mathrm{CO} / 2 \mathrm{~mol}$ amino acid [17].

For solid adsorbents, the tradeoff of capacity and energy use has resulted in processes with heats of adsorption in the range of 50$80 \mathrm{~kJ} / \mathrm{mol}$, i.e., chemi- rather than physisorption, and a thermodynamic argument can be made that this range is optimal [18]. The theoretical energy for $\mathrm{CO}_{2}$ separation from air is approximately $20 \mathrm{~kJ} / \mathrm{mol}$. This means that, unless the heat of adsorption is recovered, the maximum theoretical first law efficiency lies somewhere in the range of $20-40 \%$. Solid adsorption processes operate at low temperatures but have thus far immobilized the sorbent on solid supports that add to the parasitic load of heating and cooling the contacting device. A typical example of the heating required in a solid adsorbent system is given below (Table 1), based on properties from [20].

This leads to a minimum heat requirement of $960 \mathrm{kwh}_{t h} /$ tonne of $\mathrm{CO}_{2}$. The heat of adsorption is $410 \mathrm{kwh}_{t h} / \mathrm{ton}$, which means to achieve high efficiencies it is necessary to recover as much of the sensible heat applied to the contactor as possible, but given the low operating temperature, this is a significant challenge. The cost of this heat depends on whether this is being provided directly through 
Table 1. Properties of a solid adsorbent DAC system

\begin{tabular}{lcc}
\hline \hline \multicolumn{1}{c}{ Property } & Value & Units \\
\hline Mass ratio contactor to solid adsorbent & $1: 1$ & \\
Heat capacity solid adsorbent & 890 & $\mathrm{~J} / \mathrm{kg} /{ }^{\circ} \mathrm{C}$ \\
Heat capacity contactor & 850 & $\mathrm{~J} / \mathrm{kg} /{ }^{\circ} \mathrm{C}$ \\
$\mathrm{CO}_{2}$ swing capacity of adsorbent & 1.5 & $\mathrm{~mol} \mathrm{CO} / \mathrm{kg}$ sorbent \\
Temperature swing & 75 & ${ }^{\circ} \mathrm{C}$ \\
Heat of sorption & 65 & $\mathrm{~kJ} / \mathrm{mol} \mathrm{CO}_{2}$ \\
\hline
\end{tabular}

natural gas combustion, for example, or by steam at the bottom of a power cycle. If it is assumed that the system has $50 \%$ efficiency and requires double the energy calculated above, i.e., $2,000 \mathrm{kwh}_{t h} /$ ton, then in the former case, the cost would be approximately $\$ 35$ / ton $\mathrm{CO}_{2}$ if natural gas is priced at $\$ 5 / \mathrm{GJ}$. This assumes that in the $50 \%$ efficiency case any adsorption and desorption of water by the adsorbent is included. The behavior of many solid $\mathrm{CO}_{2}$ adsorbents under humid conditions is not well characterized and $\mathrm{CO}_{2} / \mathrm{H}_{2} \mathrm{O}$ co-management remains a weakness in current DAC analyses based on solid adsorption processes. On the other hand, if the steam is at low pressure after we have extracted power from it, then the cost would be roughly $1 / 5^{\text {th }}$ of the above number or $\$ 6 /$ ton. This is based on conventional natural gas combined cycle power generation, because of the limited quantity of useful work that can be extracted from it.

The quality of the heat required is a critical issue for DAC systems. The energy use in DAC may be higher than for other capture processes that address more concentrated feeds, but if this energy is required at the level of waste heat, then the cost of the energy is less of a factor and no new $\mathrm{CO}_{2}$ is being released when the waste heat is used. This same analysis can be applied to other sorbent processes, such as liquid-based absorption processes. From an energy efficiency perspective, therefore, the goal is to find materials with appropriate heats of sorption that can operate at moderate temperatures and have low parasitic heat loads either by being highly concentrated in the case of liquids, or requiring minimal mass in the case of solids; both cases benefit from low heat capacity. None of the materials developed for DAC meets all the desired energy efficiency metrics, and thus this is an opportunity for innovation for the chemical and materials engineering.

In situations where energy comes at low cost because of exploiting heat at low temperatures or using renewable energy during periods where supply exceeds demand, energy efficiency may be of less importance, and instead the focus should switch to the required capital to support the process. However, if excess renewable energy is used, then the system will operate only part of the time and this results in low on-stream factors, increasing the total cost of the capture process per ton because of inefficient use of capital. Thus, it is important to identify ways in which low temperature DAC systems can be heat integrated with other steady state processes. This should be done both to exploit low temperature waste heat that might otherwise be rejected to the environment, and to devise effective ways to capture and reuse the DAC process heat not required for $\mathrm{CO}_{2}$ desorption. This will ultimately enable a low capture cost.

\section{DAC CARBON FOOTPRINT}

The carbon footprint of DAC is mostly determined by its energy source. An accepted approach to DAC capture is to also capture the $\mathrm{CO}_{2}$ of any fossil combustion, sometimes in a separate system from the DAC because of the higher $\mathrm{CO}_{2}$ concentration in the flue gas. This leads to an important metric for DAC systems: the ratio of the $\mathrm{CO}_{2}$ captured from the air to the total $\mathrm{CO}_{2}$ captured. If a $\mathrm{CO}_{2}$ footprint of $63.8 \mathrm{~kg}-\mathrm{CO}_{2} \mathrm{e} / \mathrm{Gigajoule}$ of natural gas [19] is used, then the above energy requirements of $2,000 \mathrm{kwh}_{t h}$ and 125 $\mathrm{kwh}_{e} /$ ton produced from a combined heat and power unit would mean that the ratio would be 0.53 , i.e., roughly half the $\mathrm{CO}_{2}$ captured comes from the energy required to power the process. This demonstrates the importance of both reducing the energy required and the carbon footprint of the energy itself. Fixed capital and sorbent production footprints could be a significant percentage of the overall cost if the sorbent lifetime is short and the source of the energy has a very low carbon footprint [21]. For instance, estimates are $45 \mathrm{~kg} \mathrm{CO}_{2} \mathrm{e}$ for the sorbent for a TVSA process and $15 \mathrm{~kg} \mathrm{CO}_{2} \mathrm{e}$ for the plant construction per ton of $\mathrm{CO}_{2}$ captured, which is roughly $10 \%$ of the carbon footprint of the natural gas energy.

The above argument suggests that once an acceptable energy efficiency in the regeneration step (heuristically about 3-5 GJ/ton) is realized, overall energy costs in the $\$ 10-20 /$ ton range will be achieved, suggesting that the focus should shift to reducing capital costs. At the process level, system size and, therefore capital cost, is related to system productivity, expressed as mass of $\mathrm{CO}_{2}$ per unit of sorbent per time, which is a function of the rate of adsorption and desorption. This implies improving rates of heat and mass transfer and ensuring that the kinetics of the sorption are fast enough to keep up with these transfer processes. The improvement of transfer rates, both during the capture and regeneration steps, enables cycles to be faster and hence increases the productivity of the sorbent. The dilute nature of the stream during capture has so far meant that this is the step that has the slowest mass transfer kinetics and longest duration. This leads us to consider the design of the contactor as one the most important choices.

\section{CONTACTOR DESIGN CONSIDERATIONS}

Regardless of the sorption chemistry of any DAC system, a primary consideration is how the air will be contacted with the reactant that captures the $\mathrm{CO}_{2}$. For example, in the 2011 American Physical Society report, the contactor envisioned was like that of flue-gas capture where the gas is bubbled through a liquid column. This led to a very high cost of moving the air and large column sizes, and it has been recognized that instead, contacting must be done with low pressure drop in systems where the internal space is mostly occupied by air. From a contactor design perspective, the key tradeoffs are balancing the rate of mass transfer to the adsorbent with the pressure drop through the contactor. For solid adsorber contactors, during the desorption phase, increasing the rate of heat transfer to the adsorbent without unacceptably low energy efficiency is a further consideration.

To make each of these tradeoffs more concrete, consider the pressure drop and its impact on the cost of capture. Capturing one 
ton of $\mathrm{CO}_{2}$ requires moving about 2 million $\mathrm{m}^{3}$ of air, if $50 \%$ of the $\mathrm{CO}_{2}$ is removed, or if we want to capture 1 million tons/year, we will be moving roughly $73,000 \mathrm{~m}^{3}$ of air per second. A typical air velocity for capture is $5 \mathrm{~m} / \mathrm{sec}$, so we require an overall diameter of $150 \mathrm{~m}$ through which to flow the air. This is not very different from the diameter of a large modern wind turbine. If we assume a pressure drop of $250 \mathrm{~Pa}$ and have to provide the kinetic energy of the air, this results in a power demand of roughly $20 \mathrm{MW}$, which translates to $150 \mathrm{kwhe} / \mathrm{ton}$ of $\mathrm{CO}_{2}$. This is of order of magnitude $\$ 10 /$ ton, which is a relatively modest cost and is significantly lower than the energy required for the $\mathrm{CO}_{2}$ desorption as calculated above. The key is thus to keep pressure drops in the 100's of pascal range to avoid excess energy cost and the need for high power fans, or worse, compressors. For low pressure drops at these velocities the contactor will need to be short, the porosity reasonably high, and the auxiliary pressure drop through any associated equipment minimized. This pressure drop consideration is balanced by the need to provide high levels of mass transfer area per unit volume, which is needed to increase the productivity of the system via increases in the mass (and heat) transfer rates.

The transport limitations are different for liquid vs solid contactors. To illustrate this point we will examine the transport processes for two systems that have been described in the literature [15,22], the alkali based liquid absorption system and the polyamine solid adsorbent system.

The transfer processes for $\mathrm{KOH}$ solution absorbents were analyzed by Holmes et al. [15]. The key result was that the rate of transfer across the liquid film is of order $1 \mathrm{mg} \mathrm{m}^{-2} \mathrm{sec}^{-1}$ and that each kilogram of solution absorbs $20 \mathrm{~g}$ of $\mathrm{CO}_{2}$ before returning to regeneration. The capture flux, adapted from [15] is given in Eq. (1):

$$
\mathrm{N}=\rho_{\mathrm{CO}_{2}} \mathrm{u}\left(1-\mathrm{e}^{-\varepsilon a d^{K_{L} / u}}\right)
$$

The quantities in this equation are copied from [15] and given in Table 2 below.

As an example of a solid adsorption process, Kalyanaraman et al. [22] developed an adsorption/desorption kinetic model to describe the mass transfer of $\mathrm{CO}_{2}$ within PEI-functionalized cellulose acetate/silica hollow fibers. This model was based on two different amine adsorption sites on impregnated PEI where the ratio between exposed amines to the total amine sites on aminopolymer chains depends on amine loading of the fiber sorbents. It uses the standard linear driving force model for $\mathrm{CO}_{2}$ mass transfer, and so the rate decreases as the solid sorbent becomes saturated with $\mathrm{CO}_{2}$ during the adsorption. It is assumed that $\mathrm{CO}_{2}$ mass transfer is the rate limiting step rather than $\mathrm{CO}_{2}$ chemisorption reaction rates on amine-functionalized adsorbents.

To compare this approach with liquid systems we adopted a hypothetical laminate contactor where a porous laminate sheet has embedded porous silica particles with impregnated aminopolymers, leading to a series of mass transfer resistances. The channel is formed from two parallel sheets having an air channel length of $0.3 \mathrm{~m}$ and spacing of roughly $3 \mathrm{~mm}$. The amount of $\mathrm{CO}_{2}$ captured by the laminate contactor at any given time and point in space is also given based on the linear driving force approximation.

$$
\frac{\partial \mathrm{q}}{\partial \mathrm{t}}=\mathrm{K}_{o v}\left(\mathrm{q}_{e q}-\mathrm{q}(\mathrm{t})\right)
$$

Here, $\mathrm{K}_{o v}$ is the overall mass transfer coefficient and $\mathrm{q}_{e q}$ is the equilibrium $\mathrm{CO}_{2}$ capacity at given temperature and $\mathrm{CO}_{2}$ partial pressure of the flowing air at the point in the contactor. Therefore, to zeroth order, capture flux is given in the equation below.

$$
\mathrm{N}=\frac{\rho_{\text {sorbent }} \mathrm{MW}_{\mathrm{CO}_{2}} \mathrm{~K}_{\text {ov }}\left(\mathrm{q}_{\text {eq }}-\mathrm{q}\right)}{\mathrm{A}_{s}}
$$

Table 2. Parameters for alkali absorption process [15]

\begin{tabular}{lccl}
\hline \hline Quantity & Value & Units & Description (value used for calculating N) \\
\hline $\mathrm{N}$ & $1.05 \times 10^{-3}$ & $\mathrm{~kg} / \mathrm{m}^{2} / \mathrm{sec}$ & $\mathrm{CO}_{2}$ capture flux, $\mathrm{m}^{2}$ is the inlet area \\
$\rho_{\mathrm{CO}_{2}}$ & $7.3 \times 10^{-4}$ & $\mathrm{~kg} \mathrm{CO} / \mathrm{m}^{3}$ air & Density of $\mathrm{CO}_{2}$ at $400 \mathrm{ppmv}$ \\
$\mathrm{u}$ & $1-2$ & $\mathrm{~m} / \mathrm{sec}$ & Velocity of air $(2)$ \\
$\varepsilon$ & 0.8 & -- & Packing efficiency \\
$\hat{\mathrm{a}}$ & 210 & $\mathrm{~m}^{2} / \mathrm{m}^{3}$ & Specific surface area of packing \\
$\mathrm{d}$ & $5-15$ & $\mathrm{~m}$ & Depth of packing (10) \\
$\mathrm{K}_{L}$ & $1.5 \times 10^{-3}$ & $\mathrm{~m} / \mathrm{sec}$ & Liquid phase mass transfer coefficient \\
\hline
\end{tabular}

Table 3. Parameters for solid adsorption process mass transfer analysis

\begin{tabular}{lccl}
\hline \hline Quantity & Value & Units & Description \\
\hline $\mathrm{N}$ & $4.39 \times 10^{-2}$ & $\mathrm{~kg} \mathrm{CO} / \mathrm{m}^{2} / \mathrm{sec}$ & $\mathrm{CO}_{2}$ capture flux, $\mathrm{m}^{2}$ is the inlet area \\
$\mathrm{MW}_{\mathrm{CO}_{2}}$ & 44.01 & $\mathrm{~kg} \mathrm{CO} / \mathrm{kmol} \mathrm{CO}_{2}$ & Molecular weight of $\mathrm{CO}_{2}$ \\
$\rho_{\text {sorbent }}$ & 600 & $\mathrm{~kg} \mathrm{sorbent} / \mathrm{m}^{2}$ sorbent & Sorbent density \\
$\mathrm{u}$ & $2-5$ & $\mathrm{~m} / \mathrm{sec}$ & Velocity of air $(2)$ \\
$\mathrm{A}_{s}$ & 3.33 & $\mathrm{~m}^{2} / \mathrm{m}^{3}$ & Inlet area of a channel normalized by the sorbent volume \\
$\mathrm{L}$ & 0.3 & $\mathrm{~m}$ & Channel length \\
$\mathrm{k}_{g}$ & $3.60 \times 10^{-2}$ & $\mathrm{~m} / \mathrm{sec}^{-1}$ & Gas convective mass transfer coefficient \\
$\mathrm{K}_{o v}$ & $2.03 \times 10^{-3}$ & $\mathrm{sec}^{-1}$ & Overall mass transfer coefficient \\
\hline
\end{tabular}


Table 4. Results from laminate solid adsorption process mass transfer analysis

\begin{tabular}{|c|c|c|c|c|c|}
\hline \multirow{2}{*}{$\begin{array}{l}\text { Quantity } \\
\mathrm{K}_{o v}\end{array}$} & \multirow{2}{*}{$\begin{array}{l}\text { Units } \\
\sec ^{-1}\end{array}$} & \multicolumn{2}{|c|}{$\begin{array}{l}\text { Start of the concentration front } \\
\text { (Fresh adsorption) }\end{array}$} & \multicolumn{2}{|c|}{$\begin{array}{l}\text { Behind of the concentration front } \\
\text { (Half saturated) }\end{array}$} \\
\hline & & $2.03 \times 10^{-3}$ & $7.13 \times 10^{-4}$ & $1.17 \times 10^{-4}$ & $4.46 \times 10^{-5}$ \\
\hline $\mathrm{C}_{\mathrm{CO}_{2}}$ & ppm & 400 & 200 & 400 & 200 \\
\hline $\mathrm{N}$ & $\mathrm{kg} \mathrm{CO} / \mathrm{m}^{2} / \mathrm{sec}$ & $4.39 \times 10^{-2}$ & $1.51 \times 10^{-2}$ & $1.91 \times 10^{-3}$ & $7.12 \times 10^{-4}$ \\
\hline
\end{tabular}

Since the $\mathrm{CO}_{2}$ mass transfer is the rate limiting step in $\mathrm{CO}_{2}$ adsorption, the capture flux is based on the inlet area of the air channels $\left(\mathrm{A}_{\mathrm{s}}\right)$. The quantities used in the calculation are given in Table 3 .

The $\mathrm{CO}_{2}$ capture flux in fresh sorbents across the laminate surfaces is of order of $44 \mathrm{mg} \mathrm{m}^{-2} \mathrm{sec}^{-1}$, which is larger than the liquid film absorption at the same air velocity, assuming that the air has a constant concentration of $\mathrm{CO}_{2}$. Note that as a result of the faster $\mathrm{CO}_{2}$ mass transfer and higher specific surface area of the solid contactors, the contactor length is smaller in solid contactors than liquid contactors $(0.3 \mathrm{~m}$ vs. $10 \mathrm{~m})$, which has the simultaneous beneficial effect of lowering the pressure drop.

However, it should be recognized that this is an upper bound on the capture flux: the channel does not see 400 ppm concentrations combined with a zero loaded sorbent along its entire length at all times. Instead, a $\mathrm{CO}_{2}$ concentration front moves along the length of the channel during $\mathrm{CO}_{2}$ adsorption and the sorbent becomes nearly saturated behind the front leading to a near zero flux for those parts of the channel later in the cycle and lower fluxes ahead of the front due to lower $\mathrm{CO}_{2}$ concentrations. This implies that we should adopt relatively short cycles for the adsorption where possible to avoid having some parts of the channel material sit idle for long periods. Table 4 shows the approximate driving force for $\mathrm{CO}_{2}$ adsorption at different points of time and space during the adsorption process and the resulting capture flux. Since the $\mathrm{CO}_{2}$ adsorption in solid-supported amine sorbents is a $\mathrm{CO}_{2}$ diffusion-limited process, thus time-dependent, a system of partial differential equations (PDEs) should be numerically solved to describe the $\mathrm{CO}_{2}$ adsorption process accurately. However, even this zeroth order level of analysis clearly shows that solid contactors offer potentially higher rates of adsorption compared to liquid films with alkali absorbents as currently deployed.

\section{CONCLUSIONS}

If we are serious about keeping atmospheric concentrations within a band of 400 to $500 \mathrm{ppm}$, we are certain to need some form of negative emissions technologies, and it is likely that for hard to decarbonize sectors there may be no other alternatives. Other NET's, such as BECCS, ocean carbon sequestration and mineralization will play a role: we will need all our tools to meet ambitious climate targets. DAC offers a scalable alternative with lower spatial footprint and the ability to leverage our existing energy systems through natural gas and heat integration that offer significant advantages over these other alternatives. DAC presents a technological challenge that chemical engineers are uniquely equipped to solve with their knowledge of transfer processes and reaction engineering, combined with process engineering to synthesize effective sys- tems. Many opportunities remain for research and innovation in DAC approaches, and we hope this perspective will provide some useful guideposts.

\section{ACKNOWLEDGEMENTS}

MJR partially supported by ARPA-E under award DE21AR000008. RPL and CWJ supported as part of the Center for Understanding and Control of Acid Gas-Induced Evolution of Materials for Energy (UNCAGE-ME), an Energy Frontier Research Center funded by the U.S. Department of Energy (DOE), Office of Science, Basic Energy Sciences (BES), under award \# DESC0012577.

\section{REFERENCES}

1. Z. Liu, P. Ciais, Z. Deng, R. Lei, S. J. Davis, S. Feng, B. Zheng, D. Cui, X. Dou, B. Zhu, R. Guo, P. Ke, T. Sun, C. Lu, P. He, Y. Wang, X. Yue, Y. Wang, Y. Lei, H. Zhou, Z. Cai, Y. Wu, R. Guo, T. Han, J. Xue, O. Boucher, E. Boucher, F. Chevallier, K. Tanaka, Y. Wei, H. Zhong, C. Kang, N. Zhang, B. Chen, F. Xi, M. Liu, F.-M. Bréon, Y. Lu, Q. Zhang, D. Guan, P. Gong, D.M. Kammen, K. He and H.J. Schellnhuber, Nat. Commun., 11(1), 5172 (2020).

2. M. Cobb, Curr. Biol., 25(13), R526 (2015).

3. N. McGlashan, N. Shah, B. Caldecott and M. Workman, Process Saf. Environ. Prot., 90(6), 501 (2012).

4. D. McLaren, Process Saf. Environ. Prot., 90(6), 489 (2012).

5. NASEM, Negative emissions technologies and reliable sequestration: A research agenda., National Academies Press, Washington, DC (2019).

6. C. Chen and M. Tavoni, Clim. Change, 118(1), 59 (2013).

7. R. Hanna, A. Abdulla, Y. Xu and D. G. Victor, Nat. Commun., 12(1), 368 (2021).

8. M. Bui, M. Fajardy and N. Mac Dowell, Appl. Energy, 195, 289 (2017).

9. H. E. Holmes, R. P. Lively and M. J. Realff, JACS Au, 1(6), 795 (2021).

10. J. Fuhrman, H. McJeon, P. Patel, S. C. Doney, W.M. Shobe and A. F. Clarens, Nat. Clim., 10(10), 920 (2020).

11. M. Fasihi, O. Efimova and C. Breyer, J. Clean. Prod., 224, 957 (2019).

12. E. S. Sanz-Pérez, C. R. Murdock, S. A. Didas and C. W. Jones, Chem. Rev., 116(19), 11840 (2016).

13. N. McQueen, P. Kelemen, G. Dipple, P. Renforth and J. Wilcox, Nat. Commun., 11(1), 3299 (2020).

14. S. Voskian and T. A. Hatton, Energy Environ. Sci., 12(12), 3530 (2019).

15. G. Holmes and D. W. Keith, Philos. Trans. R. Soc. A, 370(1974), 4380 (2012). 
16. F. M. Brethomé, N. J. Williams, C. A. Seipp, M. K. Kidder and R. Custelcean, Nat. Energy, 3(7), 553 (2018).

17. C. A. Seipp, N. J. Williams, M. K. Kidder and R. Custelcean, Angew. Chem. Int. Ed., 56(4), 1042 (2017).

18. R. P. Lively and M. J. Realff, AIChE J., 62(10), 3699 (2016).

19. D. W. Keith, G. Holmes, D. St. Angelo and K. Heidel, Joule, 2(8), 1573 (2018).

20. A. Sinha, L. A. Darunte, C. W. Jones, M. J. Realff and Y. Kawajiri, Ind. Eng. Chem. Res., 56(3), 750 (2017).

21. S. Deutz and A. Bardow, Nat. Energy, 6(2), 203 (2021).

22. J. Kalyanaraman, Y. F. Fan, R. P. Lively, W. J. Koros, C. W. Jones, M. J. Realff and Y. Kawajiri, Chem. Eng. J., 259, 737 (2015).

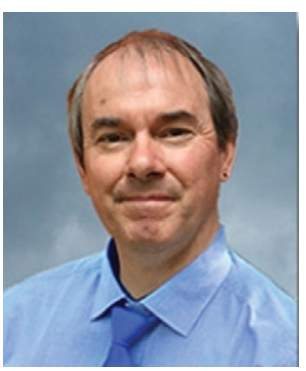

Professor Matthew J. Realff

Professor Realff is the David Wang Senior Faculty Fellow in the School of Chemical and Biomolecular Engineering at Georgia Tech. He has fostered multidisciplinary research efforts at Georgia Tech through leadership positions in the Strategic Energy Institute and Renewable Bioproducts Institute. Professor Realff received his Master's degree in Chemical Engineering from Imperial College London and his Ph.D. from MIT in the area of process systems engineering. He has been a faculty member at Georgia Tech since 1993 and was an NSF program director 2005-2007 where he led initiatives in Resilient and Sustainable systems.

Professor Realff has served as a board member of GreenBlue since 2007 which is the parent non-profit for the Sustainable Packaging Coalition a multi-stakeholder organization with over 500 members dedicated to improving packaging sustainability. He is the founding editor-in-chief of the new Journal of Advanced Manufacturing and Processing part of the AIChE Journal family. He has recently been elected a Fellow of the AIChE. 